\title{
THE LEDERMAN SCIENCE CENTER: PAST, PRESENT, FUTURE *
}

\author{
MARJORIE G. BARDEEN ${ }^{\dagger}$ \\ mbardeen@fnal.gov \\ Fermilab Education Office, Fermilab MS 226, Box 500 \\ Batavia, Illinois, 60510 United States
}

\begin{abstract}
For 30 years, Fermilab has offered K-12 education programs, building bridges between the Lab and the community. The Lederman Science Center is our home. We host field trips and tours, visit schools, offer classes and professional development workshops, host special events, support internships and have a strong web presence. We develop programs based on identified needs, offer programs with peer-leaders and improve programs from participant feedback. For some we create interest; for others we build understanding and develop relationships, engaging participants in scientific exploration. We explain how we created the Center, its programs, and what the future holds.
\end{abstract}

\section{Past}

The story of the Lederman Science Center began in 1986 after a group of middle school teachers asked to bring their students to Fermilab for a tour. They wanted the students to learn about the work of scientists and visit a scientific laboratory. The Education Office was given permission to try, but the students could not disturb the work environment.

Although students would not be able to visit the most interesting placesthe accelerator tunnel and the collision halls-we knew the students should be prepared for their visit. Education Office staff worked with a few teachers and physicists to develop an instructional unit to be taught before the field trip. We called the unit Beauty and Charm. The unit was a success, but the traditional tour was designed for adults, not for 12-year-olds.

We wanted a field trip to offer students something they could only get at the Lab. We also wanted them to learn. As Ben Franklin said, "Tell me and I forget. Teach me and I remember. Involve me and I learn." Ways to involve students

\footnotetext{
${ }^{*}$ This work is supported by the U.S. Department of Energy, the U.S. National Science Foundation and Fermilab Friends for Science Education.

${ }^{\dagger}$ Work supported by the U.S. Department of Energy.
} 
were a Q\&A with a scientist and hands-on experiments or exhibits on the tour. But the latter required dedicated space that we did not have.

What the Education Office needed was a building for students and teachers, but we were not sure how to proceed. Cynthia Yao, the wife of a member of the Fermilab Board of Overseers, gave us the answer when she shared her experience starting the Ann Arbor Hands-on Museum. With support from the director and sufficient funds, could we follow her example?

Getting Director Leon Lederman on board and in turn the Board of Overseers was easier than getting the money. We raised $\$ 25,000$ to host an expert panel and community focus groups for needs assessments. The money came with the stipulation that the new building be named for Leon, hence the Leon M. Lederman Science Education Center. The expert panel members came from several important science museums such as the Exploratorium, the Museum of Science and Industry and the St. Louis Science Center. They thought our idea an excellent one and recommended that we use a national park visitors' center as our model. That would mean content focused on Fermilab's science and technology, and a facility that included a spacious lobby to greet visitors and host events, a small "theater," exhibit space, an information kiosk and store.

Our community focus groups told us about programming. They wanted programs for children, students, teachers - everyone ages 3 to 90 in an aesthetic and functional building! They wanted creative and dynamic interactive exhibits and an educational resource center with an R\&D program for education kits and programs.

With this input, Leon was able to allocate Department of Energy (DOE) funds to design the building and make plans to build the Center using special DOE funds for general physics plant limited to $\$ 2 \mathrm{M}$ per project. Former Director Bob Wilson had a design in his hip pocket for an art museum that featured a large cantilevered roof over glass exterior walls and an open design that allowed visitors to view the art day or evening, even when the building was not open. Working from that concept, Fermlab architects came up with an aesthetic, dynamic design for the new science center. The initial cost was over budget, so the footprint became smaller, the basement and loading dock disappeared, the lobby shrank and the theater and meeting rooms were moved to a second building, to be constructed at a later date. In 2011, we are still in the original building, but we are able to schedule rooms in Wilson Hall for sessions with a scientist and for some teacher workshops.

Once we knew the size of the exhibit space, we formed a working group of physicists and physics teachers to brainstorm exhibit concepts for our field trips. The group developed 12 key ideas that we wove into a story called Quarks to 
Quasars. Some exhibit ideas lent themselves to photos or posters; others were hands-on. The target audience remained $\sim 120$ middle school students on a school field trip guided by trained docents. We felt the experience could be extended down to 10-year-olds who knew the atomic model and up to high school students in physical science classes. High school physics students who tended to come in smaller groups would go "out and about" to see some of the technical areas of the Lab such as the magnet facility, CDF or DZero work areas, or the detectors themselves when available, etc.

We created an exhibit matrix based on concept areas such as accelerators and detectors and exhibit types, interactive or not. However, we met a physicist, a former student of Leon's who worked at the Rubin H. Fleet Science Center in San Diego who took one look at the matrix and said, "Ideas, methods, tools; that's the way to organize your exhibit matrix." And so we did.

We had a modest budget but found an exhibit designer who thought working with us an interesting way to expand his portfolio. He also had middle school boys who could be his own focus group as he developed the exhibit ideas. We later found we had something else in common: our interest to have cartoons as exhibit signage matched his lifelong dream to be a cartoonist. He knew how to make our signs look like professional cartoons. We installed our exhibition that serves thousands of students each year. When we discovered that families also stopped by, we added introductory videos and printed guides for parents and grandparents.

\section{Present}

The Lederman Science Center has over 35 exhibits in four areas: Ideas-What We Study; Methods-How We Work; Tools-What We Use to Do Our Work; Accelerators and Detectors. The exhibit story and annotated list of exhibits is online at: [http://ed.fnal.gov/lsc exhibits/qtoq.html]

But the Lederman Science Center is more than exhibits for field trips. The Teacher Resource Center, science lab and technology room allow the Education Office to offer a wide range of programs associated with Fermilab physics and with Fermilab's restored prairie, a DOE National Environmental Research Park.

Today, Beauty and Charm for grades 6-8 includes the fourth edition of the original instructional unit, a teacher workshop to prepare teachers to teach the unit, the docent-led field trip that includes a visit to Wilson Hall, the Linac and Main Control Room, the Quarks to Quasars exhibits with study guides, an opportunity to meet a scientist or engineer and online materials such as Fermilabyrinth. [http://ed.fnal.gov/projects/labyrinth/games/] 
We host children in grades K-5 in our science lab after they have studied one of four topics: electricity and magnetism, light, heat, or mechanics. Scientists, engineers and computing specialists also take activities on the road visiting classrooms with interactive presentations on these and other topics. A workshop helps K-5 teachers understand and feel comfortable with these physical science concepts through facilitated exploration of a series of simple, open-ended experiments, and through discussion and reflection with a master elementary school teacher and Fermilab scientists.

Fermilab offers classes from Saturday Morning Physics for high school students in Wilson Hall to prairie rangers and science adventures for younger students at the Lederman Science Center. Typical adventures might include Lego Engineering, Magnetic Magic or Animal Architecture. Also, scout troops can complete one of 12 badges in a two-hour session. Special events include an open house and outdoor fair for families, the Wonders of Science show and a career expo for high school students.

Table 1: Current Fermilab K-12 Education Programs [http://ed.fnal.gov]

\begin{tabular}{lll}
\hline Research Experiences & Teacher Resource Center & Events for Kids \& Families \\
Academic Year High School & Resource Collections & DUSEL Education Program \\
Interns & Workshops & QuarkNet Masterclass \\
QuarkNet Summer Research & Chem West & STEM Career Fair \\
(Student/Teacher Teams) & Classroom Resources & Wonders of Science \\
TARGET & Classroom Presentations & Family Open House \\
TRAC & Data for Students & Family Outdoor Fair \\
Field Trips/High School Tours & I2U2 e-Labs \& Science & Professional Development \\
Lederman Science Center & Investigations & for Teachers \\
Physics Science Experiences & Online Resources & QuarkNet Center \\
Beauty and Charm & What is scientific research? & I2U2 Workshops \\
Phriendly Physics & Classes for Kids & Physical Sciences \\
Prairie Science Experiences & Prairie Rangers & Workshops \\
Insects at Work in Our World & Saturday Morning Physics & Prairie Workshops \\
Prairie - Our Heartland & Science Adventures & QuarkNet Boot Camp \\
Particles and Prairies & Scout Programs & QuarkNet Outreach \\
Tours & & Summer Secondary Science \\
& & Institutes \\
\hline
\end{tabular}

When focusing on teachers, the Education Office extends its influence farther than if all participants were students. The Teacher Resource Center provides a preview collection of K-12 instructional materials. TRC services include professional development workshops, consultation assistance, bibliographies and reference assistance. Educators have access to curriculum materials, books, multimedia, educational supply catalogs, periodicals and newsletters. The collection also includes reports on science and mathematics education, standards, assessment, equity and other topics. Visitors also have 
access to selective, password-protected websites. Staff is available to assist educators with curriculum and instruction issues.

Our high school program for teachers includes Summer Secondary Science Institutes in biology, chemistry and physics. Also, we are part of the national infrastructure for QuarkNet and Interactions in Understanding the Universe funded in part by the National Science Foundation and DOE.

\section{Future}

As Fermilab looks beyond the Tevatron to new research at the Intensity, Cosmic and Energy Frontiers, the Education Office looks forward to new opportunities for teachers and students - new exhibits, a new focus on discovery science as a journey, not an event.

While decades of observations and results have gone into the Standard Model, it leaves fundamental questions unanswered. What are the neutrinos telling us? Are there extra dimensions of space? What is dark matter? What is dark energy? We start with unanswered questions that stretch the imagination of physicists and students alike. We look at instruments scientists build to test their ideas and the results that support or refute them, and then follow along as physicists unravel new mysteries of particle physics. The launch of the LHC and new tours of the Tevatron, CDF and DZero allow Fermilab to be a gateway to scientific discovery, bringing students into a new era of particle physics.

Combined with the Lederman Science Center hands-on exhibits, no tour of Fermilab will be complete without a stop at the fabulous instruments that particle physicists built here. Standing next to CDF, climbing inside DZero, walking down the Tevatron tunnel will motivate students as never before.

The Leon M. Lederman Science Education Center began as a dream and has become a facility that offers opportunities for students and families to explore the science and technology of Fermilab through hands-on exhibits and programs that inspire the next generation of scientists and engineers and the citizens who support their work.

\section{Acknowledgments}

The author would like to thank Pier Oddone for continuing the tradition of Fermilab directors to give wholehearted support for the Lab's K-12 educational programming at the Lederman Science Center and to thank all those who contribute to the success of the programs - the Education Office staff, hundreds of volunteers from Fermilab's technical staff and our partners in the education community. The Fermilab Education Office is supported by the U.S. 
Department of Energy. Additional programmatic support comes from the U.S. National Science Foundation and Fermilab Friends for Science Education. 